\title{
A Study of the Short Term Effects of Faradarmani on the Frequency and Severity of Asthma Attacks
}

\author{
Mohammad Ali Taheri, Soroush Azemikhah, Ghasem Azimi, Ali Davati, Sara Saie Joeghan, and \\ Fatemeh Ashrafi-Amineh
}

\begin{abstract}
Objective: In this study, the short term effects of Faradarmani -an Iranian complementary and alternative medicine which is based on the theory of "Consciousness Bond of the Parts"- is examined on the frequency and severity of Asthma attacks. Method: 84 Asthma patients (lottery) with less than one year since diagnosis were randomly selected and divided into two groups of 42 (control and test). Spirometry was taken from both groups. The control group continued their conventional medicine treatment without the intervention of the research group. In addition to routine medicine treatment, the test group was put through Faradarmani treatment. Spirometry was repeated at the end of each month. Length of this research project was three months. Collected data was analyzed after twelve weeks. Results: In the third month of treatment, total number of severe and medium cases had reached $4.8 \%(1.8-11.3)$ in test group and $11.9 \%(1.8-21.9)$ in control group. $(21.3 \%$ decline in test, $14.3 \%$ decline in control group). The coefficient of decrease in the test group is 1.49. Decline of application of spray in the test group was 3.2 (2.18-4.19) times. Conclusion: Faradarmani had a considerable affect on the decline of the severity and frequency of Asthma attacks on patients.
\end{abstract}

Index Terms-Asthma, complementary and alternative medicine, Faradarmani, short term affect.

\section{DEFINITION OF FARADARMANI}

Any complementary and alternative method of treatment which is outside modern medical practices is called Complementary and Alternative Medicine (CAM). The National Center for Complementary and Alternative Medicine of America (NCCAM) which is affiliated to the Ministry of Health and Human Services (HHS) and the National Institute of Health (NIH), and also has close cooperation with the World Health Organization (WHO), has classified CAM into the below categories [1]:

- Energy Therapies

- Manipulative and Body Based

- Alternative Medical Systems

- Mind-Body Interventions

- Biologically Based Therapies

Faradarmani falls under the fourth category of Mind-Body Intervention and the sub-category of Mental treatment.

The present study has been performed with the aim of examining the affects of Faradarmani as a complementary

Manuscript received April 16, 2013; revised June 10, 2013.

Mohammad Ali Taheri is with Taman Universiti Johor, Malaysia (e-mail: mataheri2011@gmail.com). treatment in the trend of treatment for Asthmatic patients admitted at the Mostafa Khomeini Hospital in Tehran, Iran.

As a qualitative complementary and alternative Iranian method of treatment, Faradarmani recognizes the essence of man and takes action to improve the condition of the patient without any kind of intervention in the quantitative process of treatment. This means Faradarmani is carried out without making any intervention in classic conventional medicine or any hardware manipulation (by hardware we mean the treatments applied physically such as pharmaceutical, invasive \& surgical, physiotherapy, massage therapy, or any other similar method in which utensils and devices are to be implemented).

\section{THE THEORY OF "CONSCIOUSNESS BOND" OR "CONSTITUENTS HAVE CONSCIOUSNESS IN COMMON"}

Faradarmani is based on the theory of "Consciousness Bond" or "Constituents Having Consciousness In Common" (Fig. 1). According to this theory, when a link is established between the 'whole' consciousness and consciousness of 'constituents'; the whole consciousness-via the consciousness of the mind-is capable of correcting, repairing and curing the consciousness of constituents including mind, psyche and body, thus healing and recovery take place. Consciousness of 'constituents' consist of consciousness of the infinite numbers of human's existential constituents. The 'whole' consciousness is the awareness or consciousness governing the universe. Once a connection is made between the whole consciousness and the consciousness of a constituent, 'The Consciousness Bond' will be formed. Following that, the consciousness distribution management centre of mind will be equipped and this centre will be in contact with all parts, thus all constituents will be scanned and corrected.

\section{The Process of TREATMENT IN FARADARMANI; ESTABLiSHING ETTESAL, SCANNING STAGE, EXTERNALIZATION}

In this type of therapy, the patient becomes connected (Ettesal) to the Interuniversal Consciousness via the Fara-therapist. Following this procedure the patient undergoes the Scanning process; in other words the Universal Consciousness begins to assess and scan the individual [2]. In Faradarmani, the meaning of "Ettesal" (connection) is establishing a form of connection or link to the Interuniversal Consciousness (Figure 2). Since Ettesal is a concept originating from Mysticism, it happens merely by 
Fara-therapist's "brief attention" (called Nazar which means Glance in mysticism) which establishes a connection between the part-consciousness and the wholeconsciousness. There is no precise definition for "Ettesal" (indescribable) as it takes place in a realm 'free of tools 'and we can only study the 'effects' of Ettesal-which are indeed the subject of Faradarmani- and not the nature of Ettesal itself. Once the connection is made, its effects are manifested which is the subject of Faradarmani [3].

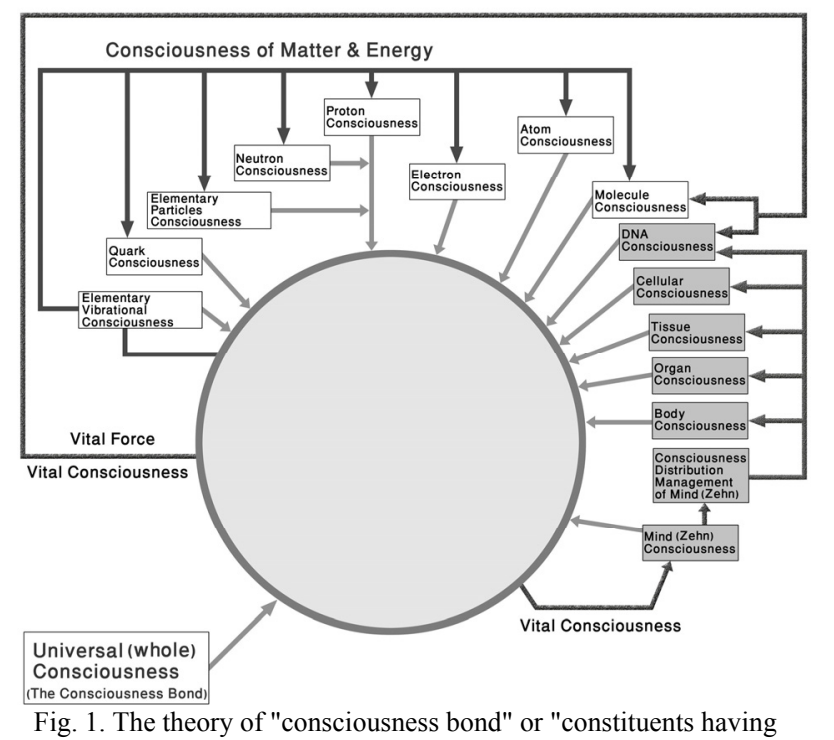
consciousness in common".

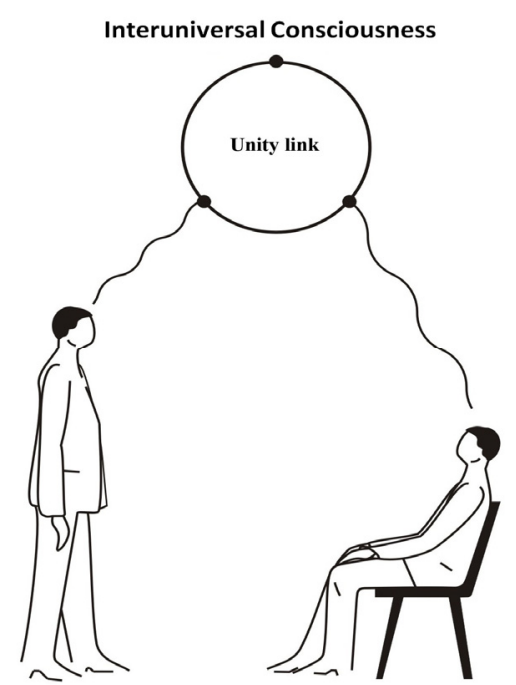

Fig. 2. Connection or link to the interuniversal consciousness.

During Ettesal, the consciousness distribution management centre of the patient's mind will be equipped and this centre will be in contact with all parts[of the patient's body]; based on the nature of this Ettesal some information is conveyed and the defective and distressed parts of the body are revealed in the form of seeing colors, lights, the feeling of movement and activity of some kind of energy throughout the body, also by feeling heat, pain, sharp aches, pulsation, twitching or convulsions and so on. In this way the patient goes through the so-called 'Scanning' process and by eliminating the symptoms, the healing process will be initiated.

Then the treatment process commences through a phase called "Externalization"; in accordance to certain patterns in Faradarmani's treatment graphs. Externalization is a process, after which a given cell reveals its present and past problems and diseases, and following that, the signs and tensions of the ailment disappear and recovery starts. The history of illnesses might even go back to the embryonic or childhood stages or may include the currently apparent diseases, also current undetected illnesses, hidden fears, emotional stresses and obstacles, mental disorders, and so on. These files could be related to any of the existential elements of the patient such as body, psyche, mind and so on. For a deep-rooted treatment to take place, the patient must tolerate the so called externalization and let these manifestations to be completed with patience.

\section{Aim of the Project, Main ObJective}

Determining the short term effect of Faradarmani on the severity and frequency of Asthma attacks

- Other objectives

- Determining the personal attributes of patients being examined in the control and test groups

- Determining the frequency of Asthma attacks in the control and test groups based on personal attributes

- Comparing the frequency of Asthma attacks in the control and test groups based on personal attributes

- Determining the severity of Asthma attacks in the control and test groups based on personal attributes

- Comparing the severity of Asthma attacks in the control and test groups based on personal attributes

\section{METhOdS}

1) Type of Study: Clinical Trial

2) Place and time of Study: The study was done during the years 2008-2009 at the Mostafa Khomeini Hospital in Tehran, Iran.

3) Sample population, method of sampling, and volume of sample: Preliminary studies have shown that the frequency and severity of attacks in over 50 percent of Asthma patients have been cured using Faradarmani. It has also been found that 10 percent of patients have recovered from the frequency and severity of Asthma attacks after undergoing one year of routine medical treatment. Meanwhile, a 20 percent dropout rate has been considered for those who might consider leaving the study program. Therefore, a sample of 84 people (42 for each group) with 95 percent confidence interval with a test potency of 90 percent in was examined.

4) Data collection tools: Survey, interview, Spirometry.

5) Methods of Data Analysis: Two dimensional and multi-dimensional charts were used for description of data along with Chi-Square, Fisher and Logit tests. The software used in this research was SPSS.

6) Ethical considerations: After teaching patients about Faradarmani and its functions, a consent form was signed based on permission to use Faradarmani parallel to drugs prescribed by their physician. The confidentiality of their personal information was also 
affirmed.

7) The study exempts from IRB review

\section{RESULTS}

84 patients entered the study and were monitored for 12 weeks. The results from this study are as follows: In comparing demographic attributes and background variation of the patients being examined, it was determined that there are no significant differences between the control and test groups; other than two demographic variations including age and period of being afflicted with the disease, and two cases using Cromolyn spray and Theophylline Tables (Table I-X).

TABLE I: The ABundance Distributions of DiseAse SEVERITY IN THE BEGINNING OF STUDY IN THE TEST AND CONTROL GROUPS

\begin{tabular}{|c|c|c|c|c|c|}
\hline & $\begin{array}{c}\text { Test } \\
\text { Number } \\
(\%)\end{array}$ & $\begin{array}{c}\text { Confidence } \\
\text { Variation } \\
(95 \%)\end{array}$ & $\begin{array}{c}\text { Control } \\
\text { Numbe } \\
\mathrm{r}(\%)\end{array}$ & $\begin{array}{c}\text { Confidence } \\
\text { Variation } \\
(95 \%)\end{array}$ & $\begin{array}{c}\text { P-Value } \\
\text { (Chi-Squar) }\end{array}$ \\
\hline Mild & $\begin{array}{c}31 \\
(83.8)\end{array}$ & $\begin{array}{c}60.1- \\
87.4 \%\end{array}$ & $\begin{array}{c}31 \\
(73.8)\end{array}$ & $\begin{array}{c}60.1- \\
87.4 \%\end{array}$ & $0.543 \mathrm{NS}$ \\
\hline $\begin{array}{c}\text { Medi } \\
\text { um }\end{array}$ & $\begin{array}{c}8 \\
(19 \%)\end{array}$ & $6.8-31.2 \%$ & $\begin{array}{c}10 \\
(23.8)\end{array}$ & $\begin{array}{c}10.5- \\
37 \%\end{array}$ & \\
\hline $\begin{array}{c}\text { Sever } \\
\text { e }\end{array}$ & $\begin{array}{c}3 \\
(7.2 \%)\end{array}$ & $0-15.1 \%$ & $\begin{array}{c}1 \\
(2.4 \%)\end{array}$ & $2.3-7.1 \%$ & \\
\hline
\end{tabular}

There was no significant difference identified for both control and test groups (Table II). The test group showed a 59.5 percent family history of Asthma, while the control group showed 61.9 percent history.

TABLE II: THE FAMILY HISTORY FOR ASTHMA

\begin{tabular}{|c|c|c|c|}
\hline & $\begin{array}{c}\text { Test } \\
\text { Number }(\%)\end{array}$ & $\begin{array}{c}\text { Control } \\
\text { Number }(\%)\end{array}$ & P-Value (Chi-Square) \\
\hline Present & $25(59.5 \%)$ & $26(61.9 \%)$ & \multirow{2}{*}{$0.823 \mathrm{NS}$} \\
\cline { 1 - 2 } Absent & $17(40.5 \%)$ & $16(38.1 \%)$ & \\
\hline Total & $42(100 \%)$ & $42(100 \%)$ & \\
\hline
\end{tabular}

The test group included $38.1 \%$ male and $61.9 \%$ female; the control group included $50 \%$ male and $50 \%$ female subjects.

TABLE III: RELATIVE ABUNDANCE OF GENDER DISTRIBUTION

\begin{tabular}{|c|c|c|c|}
\hline & $\begin{array}{c}\text { Test } \\
\text { Number }(\%)\end{array}$ & $\begin{array}{c}\text { Control } \\
\text { Number }(\%)\end{array}$ & $\begin{array}{c}\text { P-Value } \\
(\text { Chi-Square) }\end{array}$ \\
\hline Male & $16(38.1 \%)$ & $21(50 \%)$ & \multirow{2}{*}{$0.242 \mathrm{NS}$} \\
\cline { 1 - 2 } Female & $26(61.9 \%)$ & $21(50 \%)$ & \\
\hline Total & $42(100 \%)$ & $42(100 \%)$ & \\
\hline
\end{tabular}

Average age of test group subjects was 43.4 and 35.8 for control group. Period of being diagnosed with Asthma was 4.7 years in test group and 2.1 years in control group.

TABLE IV: Average Age, PERIOD of Being Diagnosed AND NuMBER of SPRAYS USED BY SUBJECTS BEFORE STUDY

\begin{tabular}{|c|c|c|c|}
\hline & $\begin{array}{c}\text { Test } \\
\text { Average } \\
\text { (Deviation) }\end{array}$ & $\begin{array}{c}\text { Control } \\
\text { Average } \\
\text { (Deviation) }\end{array}$ & P-Value \\
\hline Age & $43.4(16.9)$ & $35.8(15.1)$ & $\begin{array}{c}0.032 \text { (independent } \\
\text { tests) }\end{array}$ \\
\hline $\begin{array}{c}\text { Period of } \\
\text { Diagnosis }\end{array}$ & $4.7(5.6)$ & $2.1(1.2)$ & $\begin{array}{c}0.017 \\
\text { (Mann-Whitney) }\end{array}$ \\
\hline $\begin{array}{c}\text { Sprays } \\
\text { Used }\end{array}$ & $2.9(1.2)$ & $3.1(1.3)$ & $\begin{array}{c}0.592 \\
\text { (Mann-Whitney) }\end{array}$ \\
\hline
\end{tabular}

The average weekly administration of spray before and during study of the control and test groups was observed. Before the study, the average daily administration of spray in the test group was 2.9 times and 3.1 times in the control group. But by the end of the study, the frequency of spray administration in the test group was 1.1 and 2.7 for the control group (Table VII).

TABLE V: THE USE OF THE DRUGS

\begin{tabular}{|c|c|c|c|}
\hline & $\begin{array}{c}\text { Test } \\
\text { Number } \\
\text { (percent) } \\
\end{array}$ & $\begin{array}{l}\text { Control } \\
\text { Number } \\
\text { (percent) }\end{array}$ & $\begin{array}{c}\text { P-Value } \\
\text { (Chi-Square) }\end{array}$ \\
\hline Serotide Spray & $12(28.6 \%)$ & $13(31 \%)$ & 0.811 \\
\hline Salbutamol Spray & $33(78.6 \%)$ & $36(85.7 \%)$ & 0.393 \\
\hline Atrovent Spray & $16(38.1 \%)$ & $9(21.4 \%)$ & 0.098 \\
\hline Flouticasone Spray & $15(35.7 \%)$ & $19(45.2 \%)$ & 0.374 \\
\hline BeclomethasoneSpray & $1(2.4 \%)$ & $0(0 \%)$ & $\begin{array}{l}0.98 \text { (Fisher } \\
\text { Exact Test) }\end{array}$ \\
\hline $\begin{array}{l}\text { Cromoline Sodium } \\
\text { Spray }\end{array}$ & $3(7.1 \%)$ & $11(26.2 \%)$ & $\begin{array}{c}0.038 \text { (Fisher } \\
\text { Exact Test) }\end{array}$ \\
\hline Betametasone Tablet & $10(23.8 \%)$ & $11(26.2 \%)$ & 0.801 \\
\hline Prednisolone Tablet & $1(2.4 \%)$ & $0(0)$ & $\begin{array}{l}0.98 \text { (Fisher } \\
\text { Exact Test) }\end{array}$ \\
\hline Theophylline Tablet & $7(16.7 \%)$ & $15(35.7 \%)$ & 0.047 \\
\hline Cetirizine Tablet & $1(2.4 \%)$ & $0(0)$ & $\begin{array}{l}0.98 \text { (Fisher } \\
\text { Exact Test) }\end{array}$ \\
\hline Theophylline Syrup & $10(23.8 \%)$ & $16(38.1 \%)$ & 0.157 \\
\hline $\begin{array}{l}\text { Triamcinolone } \\
\text { Injection }\end{array}$ & $13(31 \%)$ & $21(50 \%)$ & 0.075 \\
\hline
\end{tabular}

TABLE VI: THE LEVEL OF EDUCATION OF SUBJECTS

\begin{tabular}{|c|c|c|c|}
\hline & $\begin{array}{c}\text { Test } \\
\text { Number } \\
\text { (percent) }\end{array}$ & $\begin{array}{c}\text { Control } \\
\text { Number } \\
\text { (percent) }\end{array}$ & P-Value (Chi-Square) \\
\hline Illiterate & $3(7.1 \%)$ & $1(2.4 \%)$ & \multirow{2}{*}{$0.278 \mathrm{NS}$} \\
\hline $\begin{array}{c}\text { Elementary } \\
\text { and } \\
\text { Secondary }\end{array}$ & $7(16.7 \%)$ & $2(4.8 \%)$ & \\
\hline Diploma & $14(33.3 \%)$ & $20(47.6 \%)$ & \multirow{2}{*}{0.} \\
\hline $\begin{array}{c}\text { College } \\
\text { Degree }\end{array}$ & $9(21.4 \%)$ & $8(19 \%)$ & \\
\hline $\begin{array}{c}\text { Other } \\
\text { Degrees } \\
\text { (University: } \\
\text { BA,MA, } \\
\text { PhD) }\end{array}$ & $9(21.4 \%)$ & $11(26.2 \%)$ & \\
\hline Total & $42(100 \%)$ & $42(100 \%)$ & \\
\hline
\end{tabular}

TABLE VII: THE FREQUENCY OF SPRAY ADMINISTRATION

\begin{tabular}{|c|c|c|c|c|c|c|}
\hline & 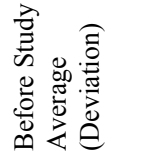 & 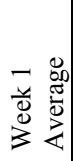 & 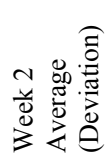 & 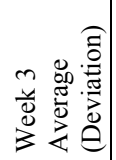 & 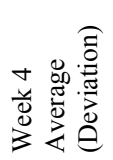 & 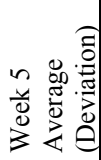 \\
\hline Test & $2.9(1.2)$ & $\begin{array}{l}2.7 \\
(1.4)\end{array}$ & $\begin{array}{l}2.6 \\
(1.3)\end{array}$ & $\begin{array}{l}2.5 \\
(1.4)\end{array}$ & $2.4(1.4)$ & $\begin{array}{l}2.3 \\
(1.1)\end{array}$ \\
\hline Control & $3.1(1.3)$ & $\begin{array}{l}2.9 \\
(1.2)\end{array}$ & $\begin{array}{l}3.2 \\
(0.8)\end{array}$ & $\begin{array}{l}3.3 \\
(1.0) \\
\end{array}$ & $3.2(0.8)$ & $\begin{array}{l}3.1 \\
(1.1)\end{array}$ \\
\hline \multirow[t]{2}{*}{ Comparison } & 0.447 & $\begin{array}{l}0.50 \\
8\end{array}$ & 0.021 & 0.003 & 0.001 & 0.00 \\
\hline & 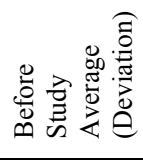 & 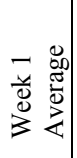 & 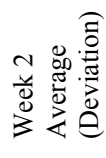 & 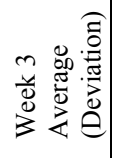 & 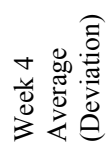 & 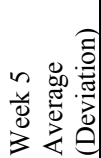 \\
\hline Test & $1.9(1.2)$ & $\begin{array}{l}1.9 \\
(1.2)\end{array}$ & $\begin{array}{l}1.8 \\
(1.3)\end{array}$ & $\begin{array}{l}1.6 \\
(1.2)\end{array}$ & $1.5(1.3)$ & $\begin{array}{l}1.1 \\
(1.0)\end{array}$ \\
\hline Control & $3.1(0.9)$ & $\begin{array}{l}3.0 \\
(0.8)\end{array}$ & $\begin{array}{l}3.1 \\
(0.9)\end{array}$ & $\begin{array}{l}3.0 \\
(0.9)\end{array}$ & $2.5(0.9)$ & $\begin{array}{l}2.7 \\
(1.0)\end{array}$ \\
\hline Comparison & 0.00 & 0.00 & 0.00 & 0.00 & 0.00 & 0.00 \\
\hline
\end{tabular}

Use of Friedman's ANOVA analysis model and R.M. ANOVA has shown that the severity of Asthma has been decreased in both the control and the test groups during the three months of study. However, this decrease of severity has 
been more in the test group and during the course of the second and third months.

In the second month of treatment, the sum of severe and medium cases reached $7.1(0-15.1)$ percent in the test group and $16.6(5-28.2)$ percent in the control group. This indicates a 19 percent decrease in the test group and a 9.6 percent decrease in the control group in comparison with the beginning of the treatment (The ratio of decrease in the test group to the control group is 1.97 times).

TABLE VIII: THE SEVERITY OF ASTHMA IN THE FIRST MONTH AFTER START

\begin{tabular}{|c|c|c|c|c|c|}
\hline & $\begin{array}{c}\text { Test } \\
\text { Number } \\
(\%)\end{array}$ & $\begin{array}{c}\text { Confidence } \\
\text { Variation } \\
(95 \%)\end{array}$ & $\begin{array}{c}\text { Control } \\
\text { Number } \\
(\%)\end{array}$ & $\begin{array}{c}\text { Confidence } \\
\text { Variation } \\
(95 \%)\end{array}$ & $\begin{array}{c}\text { P-Value } \\
\text { Chi-Square }\end{array}$ \\
\hline Normal & $0(0 \%)$ & & $1(2.4 \%)$ & $\begin{array}{l}2.3- \\
7.1 \%\end{array}$ & \multirow{5}{*}{0.090} \\
\hline Mild & $34(81 \%)$ & $\begin{array}{l}93.1- \\
68.7 \% \\
\end{array}$ & $\begin{array}{c}30 \\
(71.4 \%)\end{array}$ & $\begin{array}{l}85.4- \\
57.3 \%\end{array}$ & \\
\hline Medium & $\begin{array}{c}5 \\
(11.9 \%) \\
\end{array}$ & $\begin{array}{c}21.9- \\
1.8 \%\end{array}$ & $\begin{array}{c}11 \\
(26.2 \%) \\
\end{array}$ & $\begin{array}{l}39.8- \\
12.5 \%\end{array}$ & \\
\hline Severe & $3(7.1 \%)$ & $0-15.1 \%$ & $0(0 \%)$ & $\begin{array}{l}2.3- \\
7.1 \%\end{array}$ & \\
\hline Total & $\begin{array}{c}42 \\
(100 \%)\end{array}$ & & $\begin{array}{c}42 \\
(100 \%)\end{array}$ & & \\
\hline
\end{tabular}

TABLE IX: THE SEVERITY OF ASTHMA IN THE SECOND MONTH AFTER START OF THE STUDY

\begin{tabular}{|l|c|l|c|c|c|}
\hline & $\begin{array}{c}\text { Test } \\
\text { Number } \\
(\%)\end{array}$ & $\begin{array}{c}\text { Confidence } \\
\text { Variation (95\%) }\end{array}$ & $\begin{array}{c}\text { Control } \\
\text { Number } \\
(\%)\end{array}$ & $\begin{array}{c}\text { Confidence } \\
\text { Variation } \\
(95 \%)\end{array}$ & $\begin{array}{c}\text { P-Value } \\
\text { (Chi-Squar) }\end{array}$ \\
\hline Normal & $\begin{array}{c}16 \\
(38.1 \%)\end{array}$ & $23-53.1 \%$ & $2(4.8 \%)$ & $1.8-11.3 \%$ & 0.001 \\
\hline Mild & $\begin{array}{c}23 \\
(54.8 \%)\end{array}$ & $39.3-70.2 \%$ & $\begin{array}{c}33 \\
(78.6 \%)\end{array}$ & $\begin{array}{c}65.8- \\
91.3 \%\end{array}$ & \\
\hline Medium & $3(7.1 \%)$ & $0-15.1 \%$ & $7(16.6 \%)$ & $50-28.2 \%$ & \\
\hline Severe & $0(0 \%)$ & & $0(0 \%)$ & & \\
\hline Total & $\begin{array}{c}42 \\
(100 \%)\end{array}$ & & $\begin{array}{c}42 \\
(100 \%)\end{array}$ & & \\
\hline
\end{tabular}

TABLE X: THE SEVERITY OF ASTHMA IN THE THIRD MONTH AFTER START OF THE STUDY

\begin{tabular}{|l|c|c|c|c|c|}
\hline & $\begin{array}{c}\text { Test } \\
\text { Number } \\
(\%)\end{array}$ & $\begin{array}{c}\text { Confidence } \\
\text { Variation (95\%) }\end{array}$ & $\begin{array}{c}\text { Control } \\
\text { Number } \\
(\%)\end{array}$ & $\begin{array}{c}\text { Confidence } \\
\text { Variation } \\
(95 \%)\end{array}$ & $\begin{array}{c}\text { P-Value } \\
(\text { Chi-Square })\end{array}$ \\
\hline Normal & $32(76.2)$ & $62.9-89.4 \%$ & $\begin{array}{c}11 \\
(26.2 \%)\end{array}$ & $\begin{array}{c}12.5- \\
39.8 \%\end{array}$ & $<0.001$ \\
\hline Mild & $8(19 \%)$ & $6.8-31.2 \%$ & $\begin{array}{c}26 \\
(61.9 \%)\end{array}$ & $\begin{array}{c}46.8- \\
76.9 \%\end{array}$ & \\
\hline Medium & $2(4.8 \%)$ & $1.8-11.3 \%$ & $5(11.9 \%)$ & $\begin{array}{c}1.8- \\
21.9 \%\end{array}$ & \\
\hline Severe & $0(0 \%)$ & & $0(0 \%)$ & & \\
\hline Total & $42(100 \%)$ & & $42(100 \%)$ & & \\
\hline
\end{tabular}

In the third month of treatment, the sum of severe and medium cases reached $4.8(1.8-11.3)$ percent in the test group and 11.9 (1.8- 21.9) percent in the control group. This indicates a 21.3 percent decrease in the test group and 14.3 percent decrease in the control group in comparison with the beginning of the treatment (The ratio of decrease in the test group to the control group is 1.49 times).

Use of Friedman's ANOVA analysis model and R.M. ANOVA has also shown that with regards to the frequency of spray administration, in both the control and the test groups, the average use of spray has been decreased considerably throughout the duration of the study. However, this decline has been considerably higher in the test group in such way that the average use of spray has been decreased by 1.83 percent in the test group and by 0.47 in the control group in comparison with the beginning of the treatment. This indicates that the ratio of decrease in the test group to the control group is $3.2(2.18-4.19)$ times.

\section{CONCLUSION}

As mentioned the current study was carried out on 84 patients with Asthma who were referred to the specialized Clinic of Shahid Mostafa Khomeini Hospital and the acquired statistical results showed the significant short term effect of Faradarmani on the severity and frequency of Asthma attacks. Unfortunately no recorded research has been yet carried out in the world about the effectiveness of the complementary medical treatment of Faradarmani; nevertheless researches on the other types of complementary medical treatments have revealed extraordinary results with regards to the effectiveness of these methods.

A research about the effect of complementary and alternative medical treatments in Asthma management which was carried out by Markham [4] and his associates studied and evaluated the general results of these types of treatment in Asthma. This statistically revealed the following meaningful results in these patients: the quality of life has been improved, enhancement in pulmonary function and increase in immune system function.

Other studies about the effect of the complementary medical treatments on different types of diseases have also concluded very positive results. For instance the research carried out by Sicher [5] and his colleagues about the effect of long distance prayer on patients with AIDS, statistically revealed the following meaningful results: the need doctor visitations had decreased; the frequency of becoming hospitalized and the duration of hospitalization decreased.

In another study carried out by Luskin [6] and his colleagues, methods like yoga and meditation was used as the complementary and alternative medical treatment on patients with skeletal-muscular diseases and related disorders. The results showed that these methods were completely effective and beneficial.

Also Kennedy [7] and his colleagues' studies showed spiritual changes were effectively accompanied with increase of comfort in life, happiness, self confidence in problem solving and decrease levels of anxiety in patients. The research carried out by Mathews and his colleagues on prayer, statistically showed again meaningful and very significant recovery during one year.

In the current study, the decrease in severity of Asthma, in the test group and during the course of the second and third months has been more than the control group. In the second month of treatment, the sum of severe and medium cases reached 7.1 percent in the test group and 16.6 percent in the control group. This indicates a 19 percent decrease in the test group and a 9.6 percent decrease in the control group in comparison with the beginning of the treatment (the ratio of decrease in the test group to the control group is 1.97 times).In the third month of treatment, the sum of severe and average cases reached 4.8 percent in the test group and 11.9 percent in the control group. This indicates a 21.3 percent decrease in the test group and 14.3 percent decrease in the control group in comparison with the beginning of the treatment (the ratio of decrease in the test group to the control 
group is 1.49 times).

The results of this study meaningfully show that the correct use of Faradarmani as a complementary and alternative treatment in patients with Asthma decreases the severity of the disease and the need to consume medicine which leads to a faster recovery in comparison with the group which has only been treated by conventional treatments.

Also this type of treatment considerably lowers the treatment expenses and from economical point of view and allows the patients to recover to their initial state of productivity. The obtained results can serve as an initiative for other researchers to carry out studies of this nature, not only on patients with Asthma, but also on patients with other physical or mental problems.

Also, some questions arise in this area: Does Faradarmani also delay Asthma relapse in comparison with the group which only has received conventional medical treatment?

Would repeating this study among other groups of patients who live in other geographical areas of the country yield the same results?

How great are the economical returns of using this method of treatment alongside conventional medical treatment in patients with Asthma?

Can Faradarmani cure or control Asthma on its own? (use of this method as a alternative treatment )

How much is the effect of Faradarmani in curing other chronic pulmonary diseases as a complementary or alternative treatment?

How much is the effect of Faradarmani in curing physical diseases which are not related to respiratory system?

Considering the need and the tendency of physicians for using various complementary methods alongside conventional medicine, the introduction of an effective Iranian medicine to the global scientific society seems necessary.

Considering that no complementary medication is prescribed in Faradarmani, learning this method is easily possible through short courses, it has no interference with conventional medical treatments and is affordable and practical. Once its effectiveness is established, it could prove beneficial and cost-effective in cases where the patient must burden the costs of controlling or getting treatment for his condition.

One of the features of this method is that it does not rely on the skill or experience of the practitioner, and considering the theory of this kind of medicine, the same results are obtained when being performed by any practitioner. Therefore, it is once again suggested to facilitate the grounds for exhaustive research in this field.

\section{REFERENCES}

[1] International health organization of United Nations, The Research Centre of NCCAM, under the Supervision of Ministry of Health and National Health Organization of United State of America, 2006.

[2] R. Larijani, E. Sadeghian, and V. Riahi, "Study of faradarmani therapy on depression level," Procedia-Social and Behavioral Sciences, vol. 30, pp. 2546-2549, 2011.

[3] M. A. Taheri, Human from another Outlook, First edition. Tehran: Neda Publishing, 1386.

[4] A. W. Markham and J. M. Wilkinson, "Complementary and Alternative Medicines (CAM) in the Management of Asthma," An Examination of the Evidence, J Asthma, vol. 41, no. 2, pp. 131-139, 2004.

[5] F. Sicher, E. Targ, D. Moore, and H. S. Smith, "A randomized double-blind study of the effect of distant healing in a population with advanced AIDS," Report of a Small Scale Study, West J Med, 1998 December; vol. 169, no. 6, pp. 356-363.

[6] F. M. Luskin, K. A. Newell, M. Griffith, M. Holmes, S. Telles, E. DiNucci et al., "A review of mind/body therapies in the treatment of musculoskeletal disorders with implications for the elderly," Altern Ther Health Med, 2000 Mar., vol. 6, no. 2, pp.46-56.

[7] J. E. Kennedy, R. A. Abbott, and B. S. Rosenberg, "Changes in spirituality and well-being in a retreat program for cardiac patients," Altern Ther Health Med, July-August 2002, vol. 8, no. 4, pp. 64-66, 68-70, 72-73.

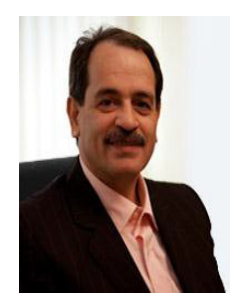

Mohammad Ali Taheri is the founder of the two Iranian complementary and alternative medicines of Faradarmani and Psymentology. He holds a BS degree in Mechanics (Turkey). After three years of research on these two C.A.M medicines, the university of traditional medicine of Armenia conferred an honorary doctorate degree in the field of complementary medicine to him (2010). The International Eco-energy Academy of the Republic of Azerbaijan also conferred upon him two honorary $\mathrm{PhD}$ degrees in complementary and alternative medicine and mysticism in two consecutive years (2009 and 2010, respectively).

Dr. Mohammad Ali Taheri has introduced Faradarmani and Psymentology and their education by publishing books and articles, attending international conference, holding educational classes, and training instructors in this science for the past two decades. Eight books and numerous articles have been published by him, and more books are being prepared for publishing (it is estimated to reach around 130 titles). The published books include: Halqeh mysticism (Iran, Andisheye Mandegar, 2009), Human from another Outlook (Iran, Bijan, 2010), Human Worldview (Iran, Tohferh, 2011), Non-organic Viruses (Armenia: Grigour Natoyasi, 2011), Human and insight (Armenia: Grigour Natoyasi, 2011), and A Collection of Articles (Armenia: Grigour Natoyasi, 2011). 